\title{
Substance use among adolescents living in slums of Guwahati city, Assam: A growing public health concern
}

\section{Tanusri Bardhan, Anku Moni Saikia, Rupali Baruah}

Department of Community Medicine, Gauhati Medical College, Guwahati, Assam, India

Address for the Correspondence:

Dr. Tanusri Bardhan, Department of Community Medicine, Gauhati Medical College, Narakasur Hilltop, Bhangagarh, Guwahati - 781 032, Assam, India. E-mail: tanubrdhn@gmail.com

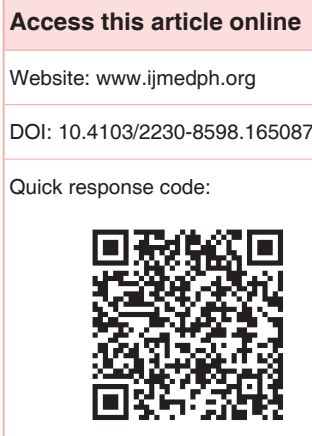

Introduction: Substance use has been a menace throughout the world for several centuries, and adolescents seem to be the most vulnerable group and the miasma of the slums adds to this multi-dimensional problem. Objectives: To study the prevalence and pattern of substance use among adolescents living in slum of Guwahati. Materials and Methods: A cross-sectional study was conducted among the adolescents living in slums of Guwahati, Assam, India during February to May 2014. Out of the total 90 slums, 23 slums were selected by cluster sampling method. For the selection of desired clusters probability proportionate to size method was applied. From each slum, equal number of boys and girls were interviewed to get a total of 414 study subjects. Statistical Analysis: Proportions and mean were used. Results: Prevalence of ever users was $37.68 \%$ and $35.02 \%$ were current users. Prevalence of substance abuse and dependence were $8.33 \%$ and $5.13 \%$ respectively. Gutkha $(83.4 \%)$ was the most common substance used. The proportion of the substance users was found to increase significantly with age in both the sexes. The mean age of initiation of the abusive substances was $12.08( \pm 2.009)$ years for males and $12.38( \pm 1.803)$ years for females. The most common reason for initiation was peer pressure $(73.1 \%)$. Shops were the main source of procuring substances. Conclusion: As significant number of adolescents is resorting to substance use, especially under the influence of peers, intensive peer group counseling is advocated. Strict implementation of legislations is emphasized, so that these young generation have no access to these dangerous substances.

Key words: Adolescents, prevalence, slums, substance use

\section{INTRODUCTION}

Human race has used substances in various forms from time immemorial and now gradually engulfing the younger generation. As per last national survey, tobacco was used by $28.6 \%$ boys and $3.5 \%$ girls, and alcohol by $11 \%$ boys and $1 \%$ girls in India. ${ }^{[1]}$ The geographical proximity to the notorious "golden triangle"[2] makes the North-Eastern states of India the most vulnerable. The miasma of the slums adds to this multi-dimensional problem. However, studies on this grave problem are scarce. This study was conducted with the objectives of studying the prevalence and pattern of substance use among slum adolescents of Guwahati.

\section{MATERIALS AND METHODS}

Guwahati is the largest city in the North-Eastern part of India and often referred to as "gateway of the North-East Region." It is the hub of social, cultural, political, and economic intersection in the region. According to 2011 census, the total population of Guwahati is 963,429 with a population density of $2695.42 / \mathrm{km}^{2}$.

A community based cross-sectional study was conducted in slums of Guwahati from ${ }^{\text {st }}$ February 2014 to $31^{\text {st }}$ May 2014. Using the prevalence of substance use among adolescents as $43.4 \%,{ }^{[3]}$ absolute precision of $7 \%$ and confidence interval of $95 \%$, sample size was calculated as 200.5 , applying the formula, $n=4 \mathrm{pq} / \mathrm{L}^{2}$. Considering a design effect of 2 , the sample size came out to be 401 . 
According to Guwahati Development Department, Government of Assam (2009), there are 90 notified slums in Guwahati city with an approximate total population of 167,796 , spread over 31 municipal wards encompassing 27,966 households approximately. ${ }^{[4]}$ From the total 90 urban slums, $1 / 4^{\text {th }}$ that is, 23 slums were selected by cluster sampling method. For the selection of desired clusters probability proportionate to size method was applied. From each slum, equal number of boys and girls were recruited. Hence, 18 adolescents ( 9 boys and 9 girls) were interviewed and so a total of 414 adolescents were taken into consideration. All adolescents (10-19 years, as defined by WHO) ${ }^{[5]}$ residing in the slums for at least last 6 months and consenting to the interview were included whereas critically ill adolescents were excluded from the study. Beforehand, an adequate rapport was built up with the community/ opinion leaders and family members of the subjects and they were interviewed mostly in the afternoon as per their convenience. A house to house visit was made in the selected slums till the desired sample size was met. Predesigned and pretested schedule was used to collect the information. Informed consent was taken either from the study subjects or their parents/guardians before the interview. At the end of the interview, appropriate referral was suggested for the adolescents using substance(s).

Ethical clearance was obtained from the Institutional Ethics Committee before the start of the study.

For the study purpose, the psychoactive substances considered were based on ICD-10 classification. ${ }^{[6]}$ For categorizing substance abuse and dependence, DSM-IV criteria were used. ${ }^{[7]}$ Data were analyzed using SPSS 16.0 (SPSS Inc., Chicago).

\section{Working definitions}

\section{Never user}

The respondent, who has not taken any of the substances ever in life, or who used fewer than 10 times in his/her entire lifetime.

\section{Ever user}

The respondent, who accepts having taken one or more substances in his/her lifetime for more than 10 times, may continue to take or has given up taking. This is further classified as current user and ex-user.

\section{Current user}

The respondent, who has taken substance(s) for more than 10 times in his/her lifetime and is currently using them during the past 1-month.

\section{Ex-user}

The respondent, who has taken a substance(s) for more than 10 times in his/her lifetime, but has given up using for at least the last 1 -month.

\section{RESULTS}

The mean age of the participants was $14.06 \pm 2.68$ years. The prevalence of ever users was found to be $37.68 \%$ and that of current users was $35.02 \%$. The study revealed that among the 156 ever users, the substance abuse and dependence was 13 (8.33\%) and $8(5.13 \%)$ respectively.

Out of 414 adolescents interviewed (males and females, 207 each), 11 adolescents $(2.66 \%)$ were ex-users. The mean duration of use by the ex-users was $2.78 \pm 0.67$ years and all of them used smokeless tobacco in the form of gutkha and they quitted due to discouragement by parents. While analyzing the relationship between various variables and substance use status, ex-users $(n=11)$ were excluded and only current users $(n=145)$ were considered. Table 1 shows the distribution of substance users in relation to age and sex. The use of substances was found to be more among the males $(68.3 \%)$ than in females $(31.7 \%)$ and it was found to be statistically significant. The prevalence of substance use was found to be more in mid (44.8\%) and late (37.3\%) adolescence.

Table 2 shows the pattern of substance use among the current users. Tobacco was the most common substance of use (83.4\%). It was found to be used in various forms and all of them used gutkha $(100 \%)$. Glue was found to be used in significant proportions in both male and female adolescents. The most common mode of use was chewing $(95.9 \%)$. The study revealed that, during the last 1-month of the interview, majority of them used the substances either 2-5 times a week $(33.1 \%)$ or daily (22.1\%). Majority of the users $(64.1 \%)$ procured the substances from the shops by self-purchase.

Most of the current users (52.4\%) started using substances during the early and mid adolescence (10-15 years). 18 (12.41\%) adolescents gave the history of initiation of substance use before the age of 10 years. The most common reason for initiation was peer pressure $(73.1 \%)$, followed by recreation $(21.4 \%)$, curiosity $(17.2 \%)$, and influence of family members (4.8\%). Majority $(63.4 \%)$ of them used the substance(s) for 1-5 years duration.

\section{DISCUSSION}

The prevalence of ever uses in the present study was $37.68 \%$. This high prevalence of substance use as found in the study could be viewed as a tip of the iceberg. It was lower than those reported in other studies conducted in different parts of India. ${ }^{[3,8]}$ The low prevalence in the present study could be

\begin{tabular}{|c|c|c|c|c|c|}
\hline Variables & $\begin{array}{c}\text { Never } \\
\text { users (\%) }\end{array}$ & $\begin{array}{c}\text { Current } \\
\text { users (\%) }\end{array}$ & df & $x^{2}$ & $P$ \\
\hline \multicolumn{6}{|l|}{$\overline{\text { Sex }}$} \\
\hline Males & $101(39.1)$ & $99(68.3)$ & 1 & 31.507 & $<0.0001$ \\
\hline Females & $157(60.9)$ & $46(31.7)$ & & & \\
\hline \multicolumn{6}{|c|}{ Age group (years) } \\
\hline $10-13$ & $156(60.5)$ & $26(17.9)$ & 2 & 79.074 & $<0.0001$ \\
\hline $14-15$ & $77(29.8)$ & $65(44.8)$ & & & \\
\hline $16-19$ & $25(9.7)$ & $54(37.3)$ & & & \\
\hline Total & 258 & 145 & & & \\
\hline
\end{tabular}




\begin{tabular}{|c|c|c|c|}
\hline \multirow[t]{2}{*}{ Variables } & Boys (\%) & Girls (\%) & Total \\
\hline & $\left(n_{1}=99\right)$ & $\left(n_{2}=46\right)$ & $(n=145)$ \\
\hline \multicolumn{4}{|l|}{ Types of substance used ${ }^{*}$} \\
\hline Tobacco products & $75(75.8)$ & $46(100.0)$ & $121(83.4)$ \\
\hline Gutkha & $75(75.8)$ & $46(100.0)$ & $121(83.4)$ \\
\hline Khaini & $14(14.1)$ & $0(0.0)$ & $14(9.7)$ \\
\hline Zarda & $3(3.0)$ & $1(2.2)$ & $4(2.8)$ \\
\hline Beedi & $33(33.3)$ & $0(0.0)$ & $33(22.8)$ \\
\hline Cigarette & $25(25.3)$ & $0(0.0)$ & $25(17.2)$ \\
\hline Alcohol & $21(21.2)$ & $0(0.0)$ & $21(14.5)$ \\
\hline Glue & $26(26.2)$ & $4(8.7)$ & $30(20.7)$ \\
\hline Ganja & $9(9.1)$ & $0(0.0)$ & $9(6.2)$ \\
\hline \multicolumn{4}{|l|}{ Mode of use* } \\
\hline \multicolumn{4}{|l|}{ Tobacco products } \\
\hline Chewing & 93 (93.9) & $46(100.0)$ & $139(95.9)$ \\
\hline Smoking & $58(58.6)$ & $0(0.0)$ & $58(40.0)$ \\
\hline Alcohol - drinking & $21(21.2)$ & $0(0.0)$ & $21(14.5)$ \\
\hline Ganja - smoking & $9(9.1)$ & $0(0.0)$ & $9(6.2)$ \\
\hline Glue - inhalation & $26(26.3)$ & $4(8.7)$ & $30(20.7)$ \\
\hline \multicolumn{4}{|l|}{$\begin{array}{l}\text { Frequency of use (any } \\
\text { substance, during the last } \\
\text { 1-month) }\end{array}$} \\
\hline$<$ Once a month & $2(2.0)$ & $0(0.0)$ & $2(1.4)$ \\
\hline Once in month & $11(11.1)$ & $2(4.3)$ & $13(9.0)$ \\
\hline 2-3 times a month & $18(18.2)$ & $8(17.4)$ & $26(17.9)$ \\
\hline Once in a week & $10(10.1)$ & $14(30.4)$ & $24(16.5)$ \\
\hline 2-5 times a week & $33(33.3)$ & $15(32.6)$ & $48(33.1)$ \\
\hline Daily & $25(25.3)$ & $7(15.2)$ & $32(22.1)$ \\
\hline \multicolumn{4}{|l|}{ Source of substances* } \\
\hline Friends & $26(26.3)$ & $18(39.1)$ & $44(30.3)$ \\
\hline Family members & $5(5.1)$ & $2(4.3)$ & $7(4.8)$ \\
\hline Shops (self-purchase) & $67(67.7)$ & $26(56.5)$ & $93(64.1)$ \\
\hline \multicolumn{4}{|l|}{ Age at initiation (years) } \\
\hline$<10$ & $12(12.1)$ & $6(13.1)$ & $18(12.4)$ \\
\hline $10-15$ & $54(54.6)$ & $22(47.8)$ & $76(52.4)$ \\
\hline $15-19$ & $33(33.3)$ & $18(39.1)$ & $51(35.2)$ \\
\hline $\begin{array}{l}\text { Mean age at initiation } \\
\text { (in years) }\end{array}$ & $12.08 \pm 2.009$ & $12.38 \pm 1.803$ & \\
\hline \multicolumn{4}{|l|}{ Duration of usage (years) } \\
\hline$<1$ & $21(21.2)$ & $12(26.1)$ & $33(22.8)$ \\
\hline $1-5$ & $62(62.6)$ & $30(65.2)$ & $92(63.4)$ \\
\hline$>5$ & $16(16.2)$ & $4(8.7)$ & $20(13.8)$ \\
\hline $\begin{array}{l}\text { Mean duration of usage } \\
\text { (in years) }\end{array}$ & $2.431 \pm 1.784$ & $2.091 \pm 1.464$ & \\
\hline
\end{tabular}

*Multiple responses

due to the inclusion of equal numbers of males and females. However, the observed prevalence was higher than those reported in a study conducted in a similar setting among male adolescents. ${ }^{[9]}$ In our study, the prevalence of substance use was found more among males than in females, which was in conformity with different studies. ${ }^{[3,10-12]}$ The use of substances among girls is largely influenced by the prevailing socio-cultural environment in this part of the globe. The use of substances increases with age and similar findings were also reported by other studies. ${ }^{[3,11]}$
In the present study, substance abuse and dependence were found to be $8.33 \%$ and $5.13 \%$, respectively. It clearly indicates that substance abuse and dependence have perpetuated the younger population to pose as another big challenge in the adolescent health.

Gutkha was the most common substance used in the present study. It is a mixture of tobacco, areca nut, catechu, slaked lime, and sweet or flavoring agent. High use of gutkha was reported in different studies across the country. ${ }^{[3,10,13]} \mathrm{A}$ remarkable finding was that a significant proportion of adolescents (20.7\%) used glue as inhalational substance. In contrast to the present finding, Benegal et al. found $2 \%$ of the children using adhesives, whereas the overall prevalence of inhalant use was $48 \%$ in their study. ${ }^{[8]}$ Glue sniffing was found to be $36.6 \%$ among $\leq 20$ years population in Spain ${ }^{[14]}$ and Hynes-Dowell et al. found that the lifetime prevalence of inhalant abuse ranges from $2.67 \%$ in Paraguay to $16.55 \%$ in Brazil. ${ }^{[15]}$

Chewing tobacco products was the most common (95.9\%) mode of using the substance, followed by smoking (40\%). This trend is exactly the reverse in case of adults as reported by Bala et al. in Gujarat, where $81.1 \%$ males and $33.9 \%$ females smoked and $15.8 \%$ males and $25.8 \%$ females chewed tobacco. ${ }^{[16]}$ This difference in mode of use of substances between adolescents and adults could be attributed to the fact that gutkha is a "gateway substance" in children and adolescents, and is the most commonly available chewable tobacco products.

An alarming finding was the high prevalence (55.2\%) of frequent users (2-5 times in a week or daily users) among this young age group. A study conducted in the youths of Tirupati reported $62.5 \%$ as weekly user and $6.3 \%$ as a daily user of alcohol. ${ }^{[17]}$ This could be an early sign that the adolescent substance users have every chance to evolve into substance abusers or dependents in the near future. Hence, an early intervention at this stage can limit such progression.

In this study, majority (64.1\%) of the adolescents procured substances from shops by self-purchase. In a study conducted by Saxena et al. in Dehradun among school going male adolescents, $21 \%$ reported to have procured the substances by self-purchase, whereas $75.5 \%$ users got the substances from their friends. ${ }^{[13]}$ This observation could have varied due to different study settings. Strict legislations on the sale of psychoactive substances are crucial in this regard.

The present study reported 18 adolescents (12.41\%) to have started using substances before the age of 10 years. Similar finding was reported by Kokiwar and Jogdand in Karimnagar ${ }^{\left[{ }^{[9}\right.}$ and Sarangi et al. in Sambalpur. ${ }^{[3]}$ In the present study, $52.4 \%$ of the current users have given the history of initiation of substance use during 10-15 years of age. Regarding the mean age of initiation of substance use, a negligible difference was observed between boys and girls that is, 12 years (for any substance). Sarangi et al. found the mean age of initiation of smoking, alcohol and cannabis is 16 years or so. ${ }^{[3]}$ Easy availability, accessibility, and social acceptability could be attributed to early initiation of substance use in the slum area. 
The leading cause of initiation of substance use was peer pressure (73.1\%). Peer pressure in this vulnerable age group was also reported by other studies, ${ }^{[3,9,17]}$ but Jain et al. found curiosity to be the most important $(68 \%)$ cause of initiation. ${ }^{[18]}$ Furthermore, in our study, $21.4 \%$ adolescents initiated substance use for recreation. Intensive peer group counseling could probably address this issue.

In relation to duration of use of substances, majority (63.4\%) of the current users have been using any substance for last 1-5 years and about $14 \%$ were using substances for more than 5 years, which is conformity to the findings of Kumar and Prabhu in Tirupati. ${ }^{[17]}$ Taking into account the impact of substance use on health, immediate interventions are required to prevent the spread of this menace.

\section{CONCLUSION}

Considering the gravity of this situation, strict implementation of legislation is emphasized, especially regarding availability and purchase of abusive substances. This study strongly recommends peer group counseling as an important intervention. As a significant proportion initiated substance use for recreation, a focused strategy on recreational and skill development programs is required. Further, a holistic approach is required involving government, nongovernmental organizations, civil societies, media, and judiciary for combating such problem.

\section{ACKNOWLEDGMENT}

The authors thank Department of Biotechnology, Ministry of Science and Technology, Government of India, for its financial support for the study.

\section{REFERENCES}

1. International Institute for Population Sciences. National Family Health Survey (NFHS-3), India 2005-06. Vol. 1. Mumbai: International Institute for Population Sciences; 2007. p. 590.

2. Golden Triangle (Southeast Asia). Available from: http://www. en.m.wikipedia.org/wiki/Golden_Triangle_(Southeast_Asia). [Last accessed on 2014 Apr 19].

3. Sarangi L, Acharya HP, Panigrahi OP. Substance abuse among adolescents in urban slums of sambalpur. Indian $\mathrm{J}$ Community Med 2008;33:265-7.
4. Notification. Dispur, Guwahati: Guwahati Development Department, Government of Assam, No. GDD.55/2006/185; February, 2009.

5. WHO. Adolescent friendly health services - An Agenda for change. Geneva: World Health Organization; 2002. p. 5.

6. WHO. The ICD-10 Classification of Mental and Behavioural Disorders - Clinical Descriptions and Diagnostic Guidelines. $10^{\text {th }} \mathrm{ed}$. Geneva: World Health Organization; 1993. p. 23.

7. American Psychiatric Association. Diagnostic and Statistical Manual of Mental Disorders. $4^{\text {th }}$ ed. Washington, DC: American Psychiatric Association; 2000.

8. Benegal V, Seshadri S, Karott M. Drug Abuse among Street Children in Bangalore. A Project in Calibration between NIMHANS, Bangalore and the Bangalore Forum of Street Children, Monograph Funded by CRY; 1998.

9. Kokiwar PR, Jogdand GR. Prevalence of substance use among male adolescents in an urban slum area of Karimnagar district, Andhra Pradesh. Indian J Public Health 2011;55:42-5.

10. Ranjan DP, Namita, Chaturvedi RM. A study of prevalence of drug abuse in aged 15 years and above in the urban slum community of Mumbai. Indian J Prev Soc Med 2010;41:117-26.

11. Qadri S, Goel RK, Singh J, Ahluwalia S, Pathak R, Bashir H. Prevalence and pattern of substance abuse among school children in Northern India: A rapid assessment study. Int J Med Sci Public Health 2013;2:273-82.

12. Juyal R, Bansal R, Kishore S, Negi KS, Chandra R, Semwal J. Substance use among intercollege students in district Dehradun. Indian J Community Med 2006;31:252-4.

13. Saxena V, Saxena Y, Kishore G, Kumar P. A study on substance abuse among school going male adolescents of Doiwala Block, District Dehradun. Indian J Public Health 2010;54:197-200.

14. Ramón MF, Ballesteros S, Martinez-Arrieta R, Torrecilla JM, Cabrera J. Volatile substance and other drug abuse inhalation in Spain. J Toxicol Clin Toxicol 2003;41:931-6.

15. Hynes-Dowell M, Mateu-Gelabert P, Barros HM, Delva J. Volatile substance misuse among high school students in South America. Subst Use Misuse 2011;46 Suppl 1:27-34.

16. Bala DV, Bodiwala IN, Patel DD, Shah PM. Epidemiological determinants of tobacco use in Gujarat state, India. Indian J Community Med 2006;31:173-6.

17. Kumar C, Prabhu GR. Prevalence of drug abuse among male youth in Tirupati, A. P. Indian J Community Med 2006;31:281.

18. Jain V, Pradhan SK, Vibha. Socio-demographic profile of 15-24 years old male narcotic substance users in a resettlement colony of Delhi. Indian J Public Health 2009;53:44-6.

How to cite this article: Bardhan T, Saikia AM, Baruah R. Substance use among adolescents living in slums of Guwahati city, Assam: A growing public health concern. Int J Med Public Health 2015;5:279-82.

Source of Support: Financial grant from Department of Biotechnology, Ministry of Science and Technology, Government of India. Conflicts of Interest: None declared. 